\title{
Avaliação dos efeitos do flunixim meglumine sobre a concentração sérica de progesterona e ciclo estral em novilhas e vacas mestiças
}

\section{Assessment on the effects of flunixin meglumine on the serum concentration of progesterone and the estrous cycle in crossbred heifers and cows}

\author{
Adalgiza Pinto Neto, ${ }^{*}$ Fabiano Mendes de Lucca, ${ }^{* *}$ Jeferson Alberton** Marcelo Falci Mota, ${ }^{* *}$ Eduardo Lucacin, ${ }^{* * *}$ \\ Alan Maia Borges, ${ }^{* \star * *}$ Alexandra Acco, ${ }^{* * * * *}$ Jeferson Ferreira da Fonseca, ${ }^{* \star * \star * * *}$ José Monteiro da Silva Filho, ${ }^{* \star * *}$ \\ Aristeu Vieira da Silva, ${ }^{\star}$ Felipe Zandonardi Brandão, ${ }^{* \star * * * * *}$
}

\begin{abstract}
Resumo
Baseando-se nos mecanismos de interrupção da síntese de PGF $_{2 \alpha}$ em bovinos, objetivou-se com este estudo avaliar os efeitos do flunixin meglumine (FM) sobre o comprimento do ciclo estral e sobre os níveis de progesterona, em novilhas e vacas mestiças. Após sincronização dos estros, os animais foram divididos em grupos: controle (cinco vacas e quatro novilhas) e tratado (seis vacas e seis novilhas), sendo submetidos à colheita diária de sangue, até o estro subseqüente. Do 13o ao 18일, aplicou-se nos animais do grupo tratado $1,65 \mathrm{mg} / \mathrm{kg}$ intramuscular de FM, e nos do grupo controle, mesmo volume de solução fisiológica. A determinação da concentração sérica de progesterona foi realizada por RIA. Os resultados do comprimento do ciclo estral foram comparados entre os grupos e entre animais, pelo teste t de Student, enquanto a concentração de progesterona foi normalizada em relação à luteólise, e analisada entre os grupos pelo teste t de Tukey (SAS). Não se observou diferença $(P>0,05)$ no comprimento do ciclo estral entre grupos e entre novilhas e vacas, tratadas e não tratadas. $O$ dia do ciclo estral em relação à concentração de progesterona máxima e inferior a 1,0ng/mL, e a concentração sérica de progesterona entre os animais do grupo controle e tratado, também foram semelhantes entre os grupos $(P>0,05)$. No entanto, observou-se diferença $(P<0,05)$ na curva que evidencia a queda da progesterona em relação ao momento da luteólise entre os animais dos grupos experimentais. Conclui-se que, embora se tenha observado efeito do tratamento, como descrito acima, sua ação seria mais bem caracterizada se a população amostral tivesse sido maior.
\end{abstract}

Palavras-chave: bovino, progesterona, luteólise, flunixin meglumine.

\begin{abstract}
This paper reports results from the assessment on the effects of flunixin meglumine (FM) on the estrous cycle and serum levels of progesterone in crossbred cows and heifers. After the estrous synchronization, the animals were separated into two groups: control ( 5 cows and 4 heifers), and experimental ( 6 cows and 6 heifers). They were submitted to daily blood sampling until the next estrus. From the $13^{\text {th }}$ to the $18^{\text {th }}$ day of the estrous cycle, each animal from the experimental group received $1.65 \mathrm{mg} / \mathrm{kg}$ of FM by intramuscular route, while animals from the control group received equal volumes of sterile saline. Levels of progesterone were measured by radio-immune-assay. The length of estrous cycle was compared among groups and individuals by Student's t-test, whereas the levels of progesterone were analyzed by Tukey's t-test. There was no significant difference in the estrous cycle length among groups and individuals. The estrous cycle day, in relation to the concentration of progesterone - highest and lower to $1.0 \mathrm{ng} / \mathrm{ml}$, and the seric concentration of progesterone among animals from both control and experimental groups were also similar $(P>0.05)$. However, there was no difference concerning the concentration of progesterone decrease among the experimental groups. It was concluded that, under the conditions this study was carried out, even though the effect of the treatment was observed, its action would be better characterized if the sample population were bigger.
\end{abstract}

Keywords: bovine, cows, heifers, progesterone, luteolysis, flunixin meglumine.

* Professores. Curso de Mestrado em Ciência Animal - UNIPAR.Umuarama-PR. Autor para correspondência

** Bolsistas de Iniciação Científica. Curso de Med. Veterinária-UNIPAR. Umuarama-PR

*** Professor. Curso de Med.Veterinária UNIPAR. Umuarama-PR

**** Mestrando em Ciência Animal-UNIPAR

***** Professores. Escola de Veterinária-UFMG. Belo Horizonte-MG

****** Professora. Farmacologia-UFPR. Curitiba-PR

******* Pesquisador CNPC-EMBRAPA. Coronel Pacheco-MG

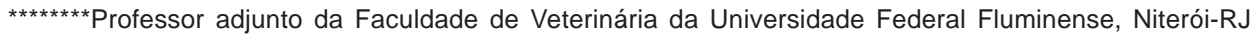

Endereço para correspondência: Rua Paulo Pedrosa de Alencar, 4491 - Zona 01 - CEP: 87501-270 - Umuarama-PR - Fone: (44) 3055-2241 res. / (44) 9956-7114 cel. / (44) 3621-2550 HV - E.mail: adalgiza@unipar.br / netoadalgiza@hotmail.com 


\section{Introdução}

No início do período gestacional, a interação entre mãe e concepto depende de mecanismos bioquímicos e endócrinos que determinam a continuidade ou não da gestação. Este período é conhecido como Reconhecimento Materno da Gestação (RMG), no qual a presença do embrião no útero sinaliza à mãe a necessidade em se manter a gestação e, em resposta, os níveis de progesterona são mantidos altos e adequados para a efetivação da gestação (Thatcher et al., 1997).

No entanto, falhas no processo de RMG, também chamado de "período crítico" podem promover a luteólise, diminuição dos níveis de progesterona e interrupção da gestação, e retorno do animal ao estro (Thatcher et al., 2001). A destruição do corpo lúteo se dá pela síntese e liberação de prostaglandinas, principalmente as do tipo $\mathrm{F}_{2 \alpha}\left(\mathrm{PGF}_{2 \alpha}\right)$, que agem ativamente no corpo lúteo promovendo, dentre outros mecanismos, a constrição de vasos que irrigam as células luteais, e conseqüente luteólise (Wathes e Lamming, 1995).

Estratégias efetivas para inibição específica de enzimas que participam da complexa síntese de $\mathrm{PGF}_{2 \alpha}$ durante o RMG, têm sido alvo de pesquisa de vários autores (Binelli et al., 2005). Alguns trabalhos foram realizados no intuito de avaliar os efeitos de antiinflamatórios não-esteroidais (AINES), fármacos sabidamente inibidores da síntese de prostaglandinas, sobre o tempo de estro e a taxa de gestação em bovinos (Elli et al., 2001; Pugh et al., 2004). O uso de ibuprofeno e de ácido acetil salicílico mostrou efeitos promissores, embora nos tratamentos descritos as drogas não tenham sido administradas no período crítico. É possível que a liberação de prostaglandina, resultante de manipulações associadas à transferência de embriões, estimule precocemente a luteólise, enquanto sua inibição poderia explicar aumento nas taxas de gestação (Pugh et al., 2004).

A administração de flunixin meglumine como agente antiluteolítico durante o período crítico, na dose de $1,1 \mathrm{mg} / \mathrm{kg}$ ao dia (Salles et al., 1998), está bem estabelecida em cabras na tentativa de impedir a regressão precoce do corpo lúteo, principalmente associada à superovulação (Soares et al., 1998). Em bovinos, entretanto, há poucos relatos conclusivos do uso deste AINE com a mesma finalidade.

Considerando que um dos mecanismos para o reconhecimento materno da gestação depende da inibição da síntese de prostaglandinas quando o metabolismo do ácido aracdônico é interrompido, a $\mathrm{PGF}_{2 \alpha}$ não é formada, o corpo lúteo não é destruído e, conseqüentemente, a concentração de progesterona é mantida suficientemente alta para o estabelecimento da gestação. Objetivou-se com este estudo avaliar o efeito antiluteolítico do flunixin meglumine, um AINE inibidor da síntese de prostaglandinas, durante 0 período de reconhecimento materno da gestação em vacas e novilhas mestiças, utilizando-se como parâmetro de avaliação o cumprimento do ciclo estral e a concentração sérica de progesterona.

\section{Material e métodos}

O experimento foi realizado nas dependências do Hospital Veterinário da Universidade Paranaense (UNIPAR), localizado no Campus II, em Umuarama, estado do Paraná, Brasil.
Utilizaram-se 24 animais mestiços, sendo 12 vacas e 12 novilhas, mantidos sob pastejo de Brachiaria sp, suplementados com cana-de-açúcar e água ad libitum. Os ciclos estrais desses animais foram sincronizados através da utilização de dispositivo intravaginal (IV), ${ }^{1}$ contendo $250 \mathrm{mg}$ de medróxi-progesterona, e aplicação intramuscular (IM) de $25 \mathrm{mg}$ de progesterona e $2 \mathrm{mg}$ de benzoato de estradiol. Sete dias após o início do tratamento, retirou-se o dispositivo IV, aplicaram-se $300 \mu \mathrm{g}$ de prostaglandina ${ }^{2}$ e, no oitavo dia, administrou-se $1 \mathrm{mg}$ de benzoato de estradiol IM. Após a retirada do implante observou-se estro, duas vezes/dia, e do oitavo ao $12^{\circ}$ dia do ciclo (estro = dia zero) os animais foram submetidos a nova aplicação de $300 \mu \mathrm{g}$ de prostaglandina. ${ }^{2}$

No dia do segundo estro (após indução da última aplicação de prostaglandina), as vacas e as novilhas foram divididas em dois grupos: controle e tratado, sendo que cada grupo foi composto por seis vacas e seis novilhas. Todos os animais foram submetidos à colheita diária de sangue do dia zero ao próximo estro.

Nos animais do grupo tratado, aplicou-se, do $13^{\circ}$ ao $18^{\circ}$ dia, $1,65 \mathrm{mg} / \mathrm{kg}$ de flunixin meglumine, por via intramuscular, enquanto nos animais do grupo controle, aplicou-se o mesmo volume de solução fisiológica.

O sangue coletado foi centrifugado, o soro extraído congelado em duas alíquotas, e encaminhado ao Laboratório de Reprodução Animal da Escola de Veterinária, da Universidade Federal de Minas Gerais (EV-UFMG), em Belo Horizonte, estado de Minas Gerais, Brasil, para determinação da concentração de progesterona, pela técnica de radioimunoensaio. ${ }^{3} \mathrm{~A}$ concentração de progesterona foi determinada nos dias zero, três, seis, nove, 12, 13, 14, 15, 16, 17 e 18 do ciclo estral.

Durante o decorrer do experimento, três animais foram eliminados do grupo controle, sendo uma vaca e duas novilhas, visto que necessitaram de tratamento clínico, inviabilizando a permanência no estudo.

Os resultados relativos ao comprimento do ciclo estral durante o ciclo estral, nos animais do grupo controle e tratado com flunixin meglumine do $13^{\circ}$ ao 18ㅇa do ciclo, foram comparados nos dias de colheita entre os grupos experimentais (controle e tratado), entre as categorias animais (vacas e novilhas) e entre as categorias/grupo, pelo teste t de Student, utilizando-se o InStat. A concentração de progesterona foi avaliada após normalização dos dados em relação ao momento da luteólise, entre os animais do grupo controle e tratado, utilizando-se o teste de comparação de médias múltiplas de Tukey, processados pelo SAS.

\section{Resultados e discussão}

Os resultados obtidos mostraram que não houve diferença no comprimento do ciclo estral de animais dos grupos tratado e controle $(23,33 \pm 4,16$ vs $23,30 \pm 3,97$ dias, respectivamente,

\footnotetext{
${ }^{1}$ Estro Forte ${ }^{\mathrm{R}}$. Estro Forte Fertilidade Animal Ltda. Umuarama-PR.

2 Prostaglandina Tortuga ${ }^{R}$. Tortuga Companhia Zootécnica Agrária. São Paulo-SP.

${ }^{3}$ Kit para progesterona - CAC fase sólida. DPC-MedLab. Maringá-PR.
} 
$P>0,05)$. Também foram encontradas diferenças entre vacas e novilhas, ou interação categoria animal $x$ tratamento $(P>0,05)$, conforme mostrado na Tabela 1.

Os resultados desse estudo diferiram daqueles apresentados por Odensvik et al. (1998), ao relatarem que a administração oral de 2,2 mg/kg de flunixin meglumine, na forma de grânulos a partir do $14^{\circ}$ dia do ciclo, durante nove dias, foi capaz de atrasar a luteólise e prolongar a duração do ciclo estral em novilhas.

Tabela 1: Duração do ciclo estral de vacas e novilhas tratadas e não tratadas com flunixin meglumine entre os dias 13 e 18 do ciclo

\begin{tabular}{lcc}
\hline $\begin{array}{c}\text { Grupos } \\
\text { experimentais }\end{array}$ & $\begin{array}{c}\text { Número de } \\
\text { animais }\end{array}$ & $\begin{array}{c}\text { Duração em dias do ciclo } \\
\text { estral }^{*}(\text { Média } \pm \text { DP) }\end{array}$ \\
\hline Grupo Controle & 9 & $23,30 \pm 3,97$ \\
Grupo Tratado & 12 & $23,33 \pm 4,16$ \\
\hline Vacas Controle & 5 & $23,33 \pm 3,93$ \\
Vacas Tratadas & 6 & $21,67 \pm 3,14$ \\
Novilhas Controle & 4 & $23,35 \pm 4,65$ \\
Novilhas Tratadas & 6 & $25,00 \pm 4,65$ \\
\hline
\end{tabular}

*Valores médios na mesma coluna não diferem ( $P>0,05)$.

Pugh et al. (2004) relataram que a administração de aspirina e flunixin meglumine no momento da transferência de embriões bovinos a receptoras possivelmente interfere na liberação de prostaglandina do tecido endometrial, decorrente da manipulação uterina no momento da transferência do embrião, impedindo assim uma luteólise prematura. Embora os autores citados não tenham utilizado o flunixim meglumine durante o período crítico, como o avaliado neste estudo, onde não se observou efeito dessa droga no prolongamento da duração do ciclo estral em novilhas e vacas mestiças.

Aiumlamai et al. (1990) e Odensvik e Gustafsson (1994) relataram que, para se prolongar o ciclo estral seriam necessárias várias administrações diárias de flunixin meglumine. Esses autores acrescentaram que a administração intravenosa e intramuscular de flunixin meglumine quatro vezes ao dia, durante sete a 10 dias, é uma estratégia farmacológica que pode manter a funcionalidade do corpo lúteo e prolongar o comprimento do ciclo estral. O mesmo foi sugerido em Ihamas, nas quais se administraram $2,2 \mathrm{mg} / \mathrm{kg}$ a cada seis horas por via intravenosa (Aba et al., 2000). É possível que a dose utilizada $(1,65 \mathrm{mg} / \mathrm{kg}$ ), a quantidade de aplicações (uma ao dia) e a duração do tratamento (seis dias) com flunixin meglumine sejam a razão dos resultados do presente estudo, pois o tempo de meia-vida desta droga após uma única injeção intramuscular em bovinos é de quatro horas, enquanto a meia-vida após quatro administrações diárias é bastante aumentada, atingindo 26 horas (Odensvik e Johansson, 1995).

Ao se normalizarem os dados para a análise da concentração de progesterona, quatro animais foram descartados (sendo dois de cada grupo) por não terem apresentado corpo lúteo ativo, ou não terem sofrido luteólise. Dessa forma, os dados foram analisados em conjunto, sem se considerar os resultados na concentração de progesterona nas novilhas e vacas separadamente.
Observou-se então que não houve diferença estatística $(P>0,05)$ no dia do ciclo estral quando a concentração de progesterona obteve valor máximo e quando atingiu valores inferiores a 1,0ng/mL, como mostra a Tabela 2.

Tabela 2: Concentração de progesterona em relação ao dia do ciclo estral em fêmeas bovinas, pertencentes ao grupo controle e tratado com flunixin meglumine

\begin{tabular}{lcc}
\hline \multicolumn{1}{c}{ Dia do ciclo estral } & \multicolumn{2}{c}{ Grupos experimentais } \\
& Controle & Tratado \\
\hline $\begin{array}{l}\text { Concentração máxima de } \\
\text { progesterona }\end{array}$ & $13,00 \pm 0,80$ & $14,27 \pm 0,74$ \\
$\begin{array}{l}\text { Concentração de progesterona } \\
\text { inferior a 1,0 } \mathrm{ng} / \mathrm{mL}\end{array}$ & $17,29 \pm 0,36$ & $17,82 \pm 0,42$ \\
\hline
\end{tabular}

Valores médios, na mesma linha, não apresentaram diferença estatística $(P>0,05)$.

A concentração sérica de progesterona por dia do ciclo estral também não apresentou diferença estatística $(P>0,05)$ entre animais do grupo controle e tratado, como mostra a Tabela 3. Esses valores talvez pudessem ser explicados em função do pequeno número de animais e da variação natural nos valores de progesterona.

Tabela 3: Concentração sérica de progesterona $(\mathrm{ng} / \mathrm{mL})$ de fêmeas bovinas pertencentes ao grupo controle e tratado com flunixin meglumine entre os dias $13 \mathrm{e}$ 18 do ciclo estral

\begin{tabular}{ccc}
\hline Dias do ciclo estral & $\begin{array}{c}\text { Grupo Controle } \\
(\mathrm{n}=10)\end{array}$ & $\begin{array}{c}\text { Grupo Experimental } \\
(\mathrm{n}=10)\end{array}$ \\
\hline $13^{\circ} \mathrm{dia}$ & $6,75 \pm 2,99$ & $6,38 \pm 3,23$ \\
$14^{\circ} \mathrm{dia}$ & $6,50 \pm 3,18$ & $6,37 \pm 2,46$ \\
$15^{\circ} \mathrm{dia}$ & $7,14 \pm 3,61$ & $5,76 \pm 3,60$ \\
$16^{\circ} \mathrm{dia}$ & $4,92 \pm 3,04$ & $4,33 \pm 3,65$ \\
$17^{\circ} \mathrm{dia}$ & $1,35 \pm 1,61$ & $3,68 \pm 4,46$ \\
$18^{\circ} \mathrm{dia}$ & $0,44 \pm 0,33$ & $1,47 \pm 2,83$ \\
\hline
\end{tabular}

*Valores médios, na mesma linha, não apresentaram diferença estatística $(P>0,05)$.

Aiumlamai et al. (1990), ao tratar novilhas com FM relataram que os níveis de progesterona mantiveram-se normais durante o tratamento, mas no mesmo período os níveis de 15-cetodihidro-PGF2 $\alpha$, um metabólito da prostaglandina, foram reduzidos e a luteólise retardada. No entanto, nesse estudo o marcador do metabolismo de prostaglandinas citado não foi mensurado.

Diferença estatística $(P<0,05)$ foi observada na curva que evidencia a queda na concentração de progesterona em relação ao momento da luteólise, entre os animais do grupo controle e tratado com flunixin meglumine, como se observa no Gráfico 1. Os valores numéricos dessa curva estão apresentados na Tabela 4. 


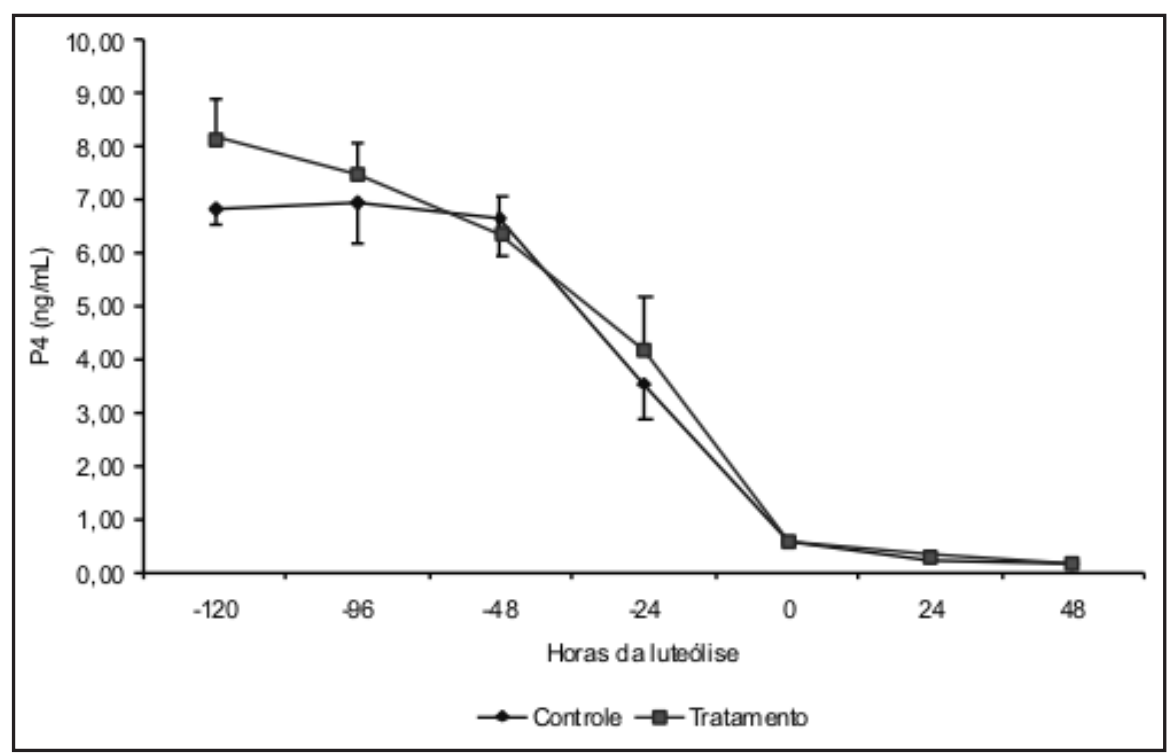

Gráfico 1: Queda na concentração de progesterona em relação ao momento de luteólise entre animais do grupo controle e tratado com flunixin meglumine.

Tabela 4: Valores médios na concentração de progesterona em relação ao momento de luteólise entre animais do grupo controle e tratado com flunixin meglumine

\begin{tabular}{ccc}
\hline Horas da luteólise & Grupo Controle & Grupo Tratado \\
\hline-120 & $6,83 \pm 0,31^{\mathrm{a}}$ & $8,16 \pm 0,76^{\mathrm{a}}$ \\
-96 & $6,96 \pm 0,78^{\mathrm{a}}$ & $7,51 \pm 0,57^{\mathrm{ab}}$ \\
-48 & $6,67 \pm 0,71^{\mathrm{a}}$ & $6,34 \pm 0,75^{\mathrm{ab}}$ \\
-24 & $3,56 \pm 0,68^{\mathrm{b}}$ & $4,18 \pm 0,99^{\mathrm{bc}}$ \\
0 & $0,57 \pm 0,10^{\mathrm{c}}$ & $0,58 \pm 0,07^{\mathrm{c}}$ \\
24 & $0,24 \pm 0,04^{\mathrm{c}}$ & $0,31 \pm 0,08^{\mathrm{c}}$ \\
48 & $0,18 \pm 0,04^{\mathrm{c}}$ & $0,17 \pm 0,03^{\mathrm{c}}$ \\
\hline
\end{tabular}

a,b,c Médias seguidas de letras diferentes, na mesma coluna, diferem $(\mathrm{P}<0,05)$

Odensvik et al. (1998) relataram que o nível de progesterona sérica é similar quando se compara o ciclo estral de novilhas tratadas e não tratadas com flunixin meglumine $(2,2 \mathrm{mg} / \mathrm{kg}-$ administração oral três vezes ao dia) durante nove dias, a complementares.

\section{Conclusão} do grupo tratado. partir do $14^{\circ}$ dia do ciclo, exceto por estender a fase luteal. Nesse estudo, os animais do grupo controle apresentaram queda abrupta na concentração de progesterona, enquanto os animais tratados apresentaram queda gradual.

A administração oral de inibidores da síntese de prostaglandinas é considerada por alguns autores uma ferramenta farmacológica para conter a liberação endógena destes eicosanóides no momento da transferência de embriões e durante o reconhecimento materno da gestação (Odensvik et al., 1998; Scenna et al., 2005). No entanto, nas condições desse estudo, a concentração de progesterona não se alterou nos animais tratados e não tratados com flunixin meglumine como mostrado na Tabela 3 , embora esses animais tenham mostrado curvas diferentes na queda da progesterona em relação à luteólise (Gráfico 1). Apesar de ter-se observado efeito do tratamento, a ação do mesmo seria mais bem caracterizada se a população amostral tivesse sido maior.

Experimentos in vitro demonstram que o FM é eficaz para reduzir de modo significativo a produção de PGE2 em útero bovino isolado, mas não provoca down-regulation de RNAm para COX2 (Braun e Kietzmann, 2004). Isto indica que outros mecanismos endócrinos ou parácrinos podem estar envolvidos na regulação das cicloxigenases e prostaglandinas no útero, abrindo perspectivas para futuros estudos

Diante dos resultados obtidos conclui-se que, nas condições desse estudo, o uso intramuscular de $1,65 \mathrm{mg} / \mathrm{kg}$ de flunixin meglumine, entre o $13^{\circ}$ e $18^{\circ}$ dia do ciclo estral, não prolongou o comprimento do ciclo estral de vacas e novilhas, e que embora a concentração de progesterona tenha sido similar entre os animais do grupo controle e tratado, a queda dessa concentração em relação à luteólise foi diferente, onde os animais do grupo controle apresentaram queda abrupta ao ser comparada com a queda gradual observada nos animais

\section{Agradecimentos}

Os autores agradecem o apoio financeiro da Diretoria de Pesquisa e Pós-Graduação da Universidade Paranaense, DEGPPUNIPAR (Projeto 696/04), da Fundação Araucária, pela concessão da bolsa de iniciação científica (PEBIC-UNIPAR), do Gerente Administrativo da Fazenda Experimental da UNIPAR, Ednei Belletini, pela disponibilização dos animais, e do Diretor do Hospital Veterinário da UNIPAR, Prof. Luiz Rômulo Alberton pela permanência dos animais durante o período experimental.

\section{Referências}

ABA, M.A.; KINDAHL, H.; FORSBERG, M.; QUIROGA, M.; AUZA, N. Levels of progesterone and changes in prostaglandine $F(2 a l p h a)$ release during luteolysis and early pregnancy in llamas and the effect of treatment with flunixin meglumine. Anim. Reprod. Sci., v. 28, n. 59 (1-2), p. 87-97, 2000.
AIUMLAMAI, S.; ODENSVIK, K.; STABENFELDT, G.; KINDAHL, H. Regulation of prostaglandin biosynthesis with flunixin meglumine in the bovine species. J. Vet. Med. A., v. 37, p. 16-22, 1990.

BINELLI, M.; MACHADO, R.; BERGAMASCHI, M.; BERTAN, C.M.; BARUSELLI, P.S. Estratégias para inibir a luteólise e aumentar a fertilidade em bovinos. Revista Brasileira de Reprodução Animal, v. 16, p. 1-6, 2005. 
BRAUN, M.; KIETZMANN, M. Ischemia reperfusion injury in the isolated hemoperfused bovine uterus - a model for the investigation of antiinflamatory substances? ALTEX, v. 21, Suppl. 3, p. 49-56, 2004.

BURNS, P.D.; GRAF, G.A.; HAYNES, S.H.; SILVIA, W.J. Cellular mechanisms by withc oxytocin stimulates uterine PGF2alpha syntesis in bovine endometrium: roles of phospholipases $\mathrm{C}$ and A2. Domest. Anim. Endocrinol., v. 14, p. 181-191, 1997.

ELLI, M.; GAFFURI, B.; FRIGERIO, A.; ZANARDELLI, M.; COVINI, D.; CANDIANI, M.; VAGINALI, M. Effect of a single dose of ibuprofen lysinate before embryo transfer on pregnancy rates in cows. Reproduction, v.121, p. 151-154, 2001.

FONSECA, J.F. Corpo lúteo acessório, perfil plasmático de progesterone e taxa de gestação de receptoras de embriões bovinos tratadas com diferentes hormônios. Dissertação (Mestrado). Belo Horizonte: UFMG, Escola de Veterinária, 1999. 93 p. .

ODENSVIK, K.; GUSTAFSSON, H. Effect of flunixin during asynchronous embryo transfer in the heifer. Anim. Reprod. Sci., v. 36, p. 13-24, 1994.

ODENSVIK, K.; GUSTAFSSON, H.; KINDAHL, H. The effect on luteolysis by intensive oral administration of flunixin granules in heifers. Anim. Reprod. Sci., v. 50, p. 35-44, 1998.

ODENSVIK, K.; JOHANSSON, I.M. High-performance liquid chromatography method for determination of flunixin in bovine plasma and pharmacokinetics after single and repeated doses of the drug. Am. J. Vet. Res. v. 56, n. 4, p. 489-95, 1995.
PUGH, M.L.; MOREIRA, M.B.; GILBERT, G.R.; YOUNGS, C.R. Influence of prostaglandin $\mathrm{R} 2 \mathrm{a}$ synthesis inhibitors on preganancy rate of embryo transfer recipient heifers. In: International Congress on Animal Reproduction, $15^{\text {th }}$., 2004, Porto Seguro, Brazil. Abstract... Belo Horizonte: CBRA, 2004. p. 399.

SALLES, H.O.; SOARES, A.T.; ANDRIOLI, A.; SOBRINHO, P.A.M.; AZEVEDO, H.C. Diferentes posologias de flunixin meglumine na prevenção da regressão prematura de corpos lúteos em cabras superovuladas. Ciência Animal, v. 8, n. 2, p. 69-74, 1998.

SCENNA, F.N.; HOCKETT, M.E.; TOWNS, T.M.; SAXTON, A.M.; ROHRBACH, N.R.; WEHRMAN, M.E.; SCHRICK, F.N. Influence of a prostaglandin synthesis inhibitor administered at embryo transfer on pregnancy rates of recipient cows. Prostaglandins Other Lip. Mediat. v. 78, n. 1-4, p. 38-45, 2005

SOARES, A.T.; SIMPLÍCIO, A.A.;ANDRIOLI-PINHEIRO, A.; SALLES, H.O.; MOURA-SOBRINHO, P.A.; AZEVEDO, H.C. Eficiência do flunixin meglumine no controle da regressão lútea prematura em cabras superovuladas. Arq. Bras. Med. Vet. Zootec., v. 50, n. 1, p. 35-39, 1998.

THATCHER, W.W.;BINELLI, M.; BURKE, J.; STAPLES, C.R.; AMBROSE, J.D.; COELHO, S. Antiluteolytic signals between the conceptus and endometrium. Theriogenology, v. 47, p. 131-140, 1997.

THATCHER, W.W.; GUZELOGLU, A.; MATTOS, R.;BINELLI, M.;HANSEN, T.R.; PRU, J.K. Uterine-conceptus interactions and reproductive failure in cattle. Theriogenology, v. 56, p. 1435-1450, 2001. 